\title{
Smoking in movies and adolescent smoking: cross-cultural study in six European countries
}

\author{
Matthis Morgenstern, ${ }^{1,2}$ Evelien A P Poelen, ${ }^{3}$ Ron Scholte, ${ }^{3}$ Solveig Karlsdottir, ${ }^{4}$ \\ Stefán Hrafn Jonsson, ${ }^{4,5}$ Federica Mathis, ${ }^{6}$ Fabrizio Faggiano, ${ }^{6,7}$ Ewa Florek$^{8}$ \\ Helen Sweeting, ${ }^{9}$ Kate Hunt, ${ }^{9}$ James D Sargent, ${ }^{10}$ Reiner Hanewinkel ${ }^{1,2}$
}

\begin{abstract}
See Editorial, p 844
${ }^{1}$ Institute for Therapy and Health Research, Kiel, Germany

${ }^{2}$ Institute for Medical

Psychology and Medical

Sociology, University Hospital

Schleswig-Holstein, Kiel,

Germany

${ }^{3}$ Behavioural Science Institute, Radboud University, Nijmegen, The Netherlands

${ }^{4}$ Directorate of Health

Reykjavik, Iceland

${ }^{5}$ University of Iceland, Reykjavik, Iceland

${ }^{6}$ Piedmont Centre for Drug Addiction Epidemiology, ASL T03, Grugliasco (TO), Italy ${ }^{7}$ Avogadro University, Novara, Italy

${ }^{8}$ Laboratory of Environmental Research, Department of Toxicology, University of Medical Sciences, Poznan, Poland

${ }^{9}$ Medical Research Council (MRC) Social \& Public Health Sciences Unit, Glasgow, UK

${ }^{10}$ Norris Cotton Cancer Center, Dartmouth Medical School, Lebanon, New Hampshire, USA
\end{abstract}

\section{Correspondence to}

Professor Reiner Hanewinkel, Institute for Therapy and Health Research (IFT-Nord)

Harmsstrasse 2, 24114 Kiel, Germany;

hanewinkel@ift-nord.de

Received 19 May 2011 Accepted 21 July 2011 Published Online First 25 August 2011

\section{ABSTRACT}

Aim To investigate whether the association between exposure to smoking in movies and smoking among youth is independent of cultural context.

Method Cross-sectional survey of 16551 pupils recruited in Germany, Iceland, Italy, the Netherlands, Poland and Scotland with a mean age of 13.4 years $(S D=1.18)$ and an equal gender distribution. Schoolbased surveys were conducted between November 2009 and June 2010. Using previously validated methods, exposure to movie smoking was estimated from the 250 top-grossing movies of each country (years 2004-2009) and related to ever smoking.

Results Overall, 29\% of the sample had tried smoking. The sample quartile (0) of movie smoking exposure was significantly associated with the prevalence of ever smoking: $14 \%$ of adolescents in 01 had tried smoking, $21 \%$ in $02,29 \%$ in 03 and $36 \%$ in 04 . After controlling for age, gender, family affluence, school performance, television screen time, number of movies seen, sensation seeking and rebelliousness and smoking within the social environment (peers, parents and siblings), the adjusted ORs for having tried smoking in the entire sample were $1.3(95 \% \mathrm{Cl} 1.1$ to 1.5$)$ for adolescents in $02,1.6$ (95\% $\mathrm{Cl} 1.4$ to 1.9$)$ for 03 and $1.7(95 \% \mathrm{Cl} 1.4$ to 2.0$)$ for 04 compared with 01 . The adjusted relationship between ever smoking and higher movie smoking exposure levels was significant in all countries with a non-linear association in Italy and Poland.

Conclusions The link between smoking in movies and adolescent smoking is robust and transcends different cultural contexts. Limiting young people's exposure to movie smoking could have important public health implications.

\section{INTRODUCTION}

Overwhelming evidence indicates that smoking is a major cause for a number of life-threatening diseases, including various cancers and cardiovascular and lung diseases. ${ }^{1} 2$ Adolescence is the developmental period in which smoking experimentation usually first occurs. ${ }^{3}$ Smoking uptake is a behavioural process that is to a large extent triggered by social risk factors. ${ }^{4}$ These social risk factors not only include peer and parental smoking but also a number of other factors such as tobacco marketing and media exposure. One prominent theory that is used to understand the smoking initiation process is social learning theory. ${ }^{5}$ This theory basically suggests that people learn by watching others. Generally, any person can function as a role model, but most likely, role models are

\section{Key messages}

What is the key question?

- There is a well-documented association between exposure to movie smoking and trying smoking among the youth in the USA and Germany. Does this apply to youths in other European countries?

\section{What is the bottom line?}

- Movie smoking exposure is associated with youth smoking, regardless of country. Much exposure comes from youth-rated movies. Given the harms of smoking, there seems to be little reason not to limit smoking in movies marketed to youth through movie ratings systems.

\section{Why read on?}

- Including more than 16000 adolescents from Germany, Iceland, Italy, Poland, Scotland and the Netherlands, this is the largest study ever conducted on this topic, and it provides some of the first evidence on the specificity of the movie smoking-youth smoking association and detailing differences in the dose-response by country.

significant social agents such as family members, peers or movie stars. ${ }^{6}$

From this perspective, it is perhaps not surprising that a number of cross-sectional, ${ }^{7-14}$ longitudinal $^{15-24}$ and experimental studies ${ }^{25-28}$ have found an association between exposure to movie smoking and smoking among adolescents. The evidence base seems so strong that a US National Cancer Institute report, ${ }^{29}$ and one from $\mathrm{WHO},{ }^{30}$ concluded that the association is "causal."

Other research has examined what share of movie smoking exposure comes from youth-rated movies; the reports have found it to be larger than half among US adolescents ${ }^{31} 32$ and even higher among adolescents in the UK. ${ }^{33}$ These facts have prompted public health advocates to call for an adult rating for smoking in movies, which is also one recommendation in the implementation guidelines of WHO's Framework Convention on Tobacco Control (FCTC). However, up to now, no country has adopted this recommendation.

The indecision of a country to change their movie ratings system may be because of lack of evidence linking movie smoking to youth smoking in that particular country. The present study 
addresses this for six European countries by reporting the results of a large-scale cross-sectional survey of young adolescents living there. These countries differ substantially in their rankings on the 2010 Tobacco Control Scale, which can be seen as an indicator for denormalising smoking in society in 30 European countries. ${ }^{34}$ The countries selected for the current study rank 1st (UK), 4th (Iceland), 12th (Italy), 13th (the Netherlands), 19th (Poland) and 26 th (Germany) on this scale. Based on data collected in 2007, the 30 day smoking prevalence among 15-16-year-olds ranged from $16 \%$ in the country with the lowest prevalence (Iceland) to $37 \%$ in the country with the highest prevalence (Italy). ${ }^{35}$

This paper aims to investigate whether the association between exposure to movie smoking and youth smoking occurs independently of cultural contexts, for example, prevalence of smoking, tobacco control policy, attitudes towards smoking in the population, culture-specific parental and peer influences.

\section{METHODS}

\section{Study sample and procedure}

The study was conducted from six study centres, in Germany (Kiel), Iceland (Reykjavik), Italy (Turin and Novara), Poland (Poznan), the Netherlands (Nijmegen) and UK (Glasgow). The six study samples were all recruited from state-funded schools (see appendix 1 for sample details). Overall, a total of 19268 students from 114 schools and 865 classes were examined for eligibility. One thousand fifty-nine students (5.5\%) could not be included in the study because of missing parental consent; 1561 students $(8.1 \%)$ were absent on the day of assessment and could not be reached by mail; 99 students $(0.5 \%)$ refused to participate, resulting in a final overall sample of 16551 students $(85.9 \%$ response rate). Within this final sample, the number of reached students per school ranged from 14 to 603, the number of reached students per class ranged from 1 to 45 students.

\section{Survey}

In each country, data were collected through self-completion questionnaires, administered by trained research staff. Each completed questionnaire was placed in an envelope and sealed in front of the class. Students were assured that their individual data would not be seen by parents or school administrators. Study implementation was approved in all six study centres by the respective ethical boards and data protection agencies.

\section{Measures}

\section{Exposure to movie smoking}

Exposure to smoking in movies was assessed using a variable data survey method developed by researchers of Dartmouth Medical School, which relies on the recall of seeing movies presented to respondents as a list of titles. ${ }^{36}$ For this procedure, each participating study centre provided a list of 250 box-office hits of their countries based on publicly available data on movie revenues. Each of the six lists of 250 movies contained the 50 most successful movies of the years 2005-2008 and the 25 most successful movies of the years 2004 and 2009. Students in each country received a random selection of 50 movies $(20 \%)$ of their country-specific list of 250, creating an individual movie list for each student. To minimise subject-to-subject disparities in movie composition, selection of movies was stratified by year of release and by country-specific age rating so that each randomly generated list of 50 titles had the same distribution with regard to year and country-specific age ratings. Students were asked to indicate how often they had seen each movie (from $0=$ 'never' to $3=$ 'more than two times'). For the present analysis, answers were dichotomised into 'seen' and 'not seen'.
In a parallel procedure, all included movies were content coded with regard to tobacco occurrences. Owing to a high overlap of box-office hits between countries, the complete sample of 1500 movies ( 6 countries $\times 250$ movies) contained 655 unique movies. Fifty-six per cent of these movies $(n=368)$ were included within the top 100 box-office hits in the USA and had already been content coded at the Dartmouth Media Research Laboratory. The remaining $44 \%(n=287)$ were content coded in the six European study centres. In this coding process, trained coders review each movie and count the number of occurrences of onscreen tobacco. A tobacco occurrence is counted whenever a major or minor character handles or uses tobacco in a scene or when tobacco use is depicted in the background (eg 'extras' smoking in a bar scene). Occurrences are counted each time the tobacco use appears on the screen. Inter-rater reliability was studied via two types of correlations: (1) between the coding results of the European coders and the European trainer on a selected number of training movies and (2) between the European trainer and the Dartmouth coders, based on a blinded European re-coding of a random sample of 40 Dartmouth-coded movies. European coder-trainer correlations ranged between $r=0.92$ (Iceland) and $r=0.99$ (Italy); the European re-counts of tobacco occurrences in the random movie selection correlated $\mathrm{r}=0.95$ with the Dartmouth counts

Exposure to movie smoking was calculated for each student by summing the number of tobacco occurrences in each movie they had seen. The measure was adjusted for possible variation in the movie lists by expressing individual exposure to movie smoking as a proportion of the total number of possible tobacco occurrences each student could have seen on the basis of the movies included in his/her questionnaire. The final exposure estimate was the proportion of seen tobacco occurrences multiplied by the total number of tobacco occurrences in the respective movie population (the number of tobacco occurrences in the 250 movies of each country).

\section{Lifetime smoking}

Students were asked "How many cigarettes have you smoked in your life?" Response categories were $0=$ "none", $1=$ "just a few puffs", $2=$ "1-19 cigarettes", $3=$ "20-100 cigarettes" and 4="more than 100 cigarettes". Students who reported "none" were classified as "never smokers" and all others as "ever smokers". ${ }^{37}$

\section{Covariates}

We included a number of covariates that could confound the relation between exposure to smoking in movies and trying smoking, including socio-demographics, behavioural and personality characteristics and smoking of peers, parents and siblings (see appendix 2). The list of covariates mirrored that of previous studies on movie smoking, ${ }^{7} 1014$ with the exception of an additional control for the number of movies seen. The control of general movie exposure strengthens the idea that the reported associations are specific to the smoking imagery because the amount of movie smoking exposure might only be a marker variable, indicating students that have high movie exposure in general.

\section{Statistical analysis}

All data analyses were conducted with Stata V.11.0 (Stata Corp, College Station, TX, USA). Bivariate associations between all study variables were analysed with Spearman rank correlation coefficients, multiple mean comparisons with Tukey test. Locally weighted scatterplot smoothings were used to graphically represent the relationship between movie smoking 
exposure and adolescent smoking for each country. For the multivariate analysis, the exposure to movie smoking was parsed into country-specific quartiles, and the dependent variable was dichotomised into ever and never smokers. The use of quartiles enabled us to directly compare the results with previous studies on movie smoking that have also used this analytic strategy. Because the data were clustered at the country, school and classroom level, associations between amount of movie smoking and lifetime smoking were analysed with multilevel mixed-effects logistic regressions with random intercepts for country, school and class in the overall analysis and random intercepts for school and class in the countryspecific models (uncentred data in all analyses). In a first step, unadjusted models were specified, with movie smoking exposure as the only fixed effect. In the adjusted models, all covariates were included as fixed effects. In each model, the first (lowest) quartile of exposure to movie smoking served as the reference category.

\section{RESULTS}

\section{Descriptive statistics}

Descriptive statistics for lifetime smoking and all covariates are presented in table 1 . The final sample consisted of 16551 students, of whom $51 \%$ were male. The mean age was 13.4 $(\mathrm{SD}=1.18)$ years, with an age range of 10 to 19 years. Overall, $29 \%$ of subjects had ever tried smoking, but this varied

Table 1 Descriptive statistics for lifetime smoking and covariates

\begin{tabular}{|c|c|c|c|c|c|c|c|}
\hline & \multicolumn{7}{|l|}{ n $(\%) *$} \\
\hline & Overall & Germany & Iceland & Italy & Poland & The Netherlands & UK \\
\hline Students & $16551(100)$ & $2754(100)$ & $2664(100)$ & $2668(100)$ & $4105(100)$ & $1423(100)$ & $2937(100)$ \\
\hline \multicolumn{8}{|l|}{ Lifetime smoking } \\
\hline Never & $11691(71)$ & $2004(73)$ & 2412 (91) & $1615(61)$ & $2377(58)$ & $970(69)$ & $2313(79)$ \\
\hline A few puffs & $2104(13)$ & $386(14)$ & $144(5)$ & $411(15)$ & $700(17)$ & $153(11)$ & $310(11)$ \\
\hline $1-19$ cigarettes & $1059(6)$ & $175(7)$ & $46(2)$ & $198(7)$ & $393(10)$ & $115(8)$ & $132(4)$ \\
\hline $20-100$ cigarettes & 661 (4) & $88(3)$ & $29(1)$ & $146(6)$ & $268(7)$ & $64(5)$ & $66(2)$ \\
\hline$>100$ cigarettes & $947(6)$ & $81(3)$ & $19(1)$ & $288(11)$ & $349(8)$ & $102(7)$ & $108(4)$ \\
\hline \multicolumn{8}{|l|}{ Socio-demographics } \\
\hline \multicolumn{8}{|l|}{ Gender } \\
\hline Female & $8088(49)$ & 1338 (49) & $1272(48)$ & $1179(44)$ & $2153(53)$ & $708(51)$ & $1438(49)$ \\
\hline Male & $8390(51)$ & $1410(51)$ & $1378(52)$ & $1485(56)$ & 1944 (47) & 677 (49) & $1496(51)$ \\
\hline Age, mean (SD) & $13.4(1.18)$ & $12.7(1.06)$ & $13.1(0.89)$ & $13.6(1.37)$ & $14.2(0.79)$ & $13.8(1.36)$ & $13.0(0.89)$ \\
\hline \multicolumn{8}{|l|}{ Family affluence } \\
\hline Low & $1637(10)$ & $231(8)$ & $40(2)$ & $364(14)$ & $687(17)$ & $29(2)$ & $286(10)$ \\
\hline Medium & $6029(36)$ & 1010 (37) & $556(21)$ & $1210(45)$ & $1728(42)$ & $385(27)$ & 1140 (39) \\
\hline High & $8885(54)$ & $1513(55)$ & $2068(77)$ & $1094(41)$ & $1690(41)$ & $1009(71)$ & $1511(51)$ \\
\hline \multicolumn{8}{|l|}{ Personal characteristics } \\
\hline \multicolumn{8}{|l|}{ School performance } \\
\hline Below average & $1253(8)$ & $171(6)$ & $113(4)$ & $390(15)$ & $368(9)$ & $122(9)$ & $89(3)$ \\
\hline Average & $5493(33)$ & $1212(44)$ & $652(25)$ & $1042(39)$ & $1576(39)$ & $407(29)$ & $604(21)$ \\
\hline Good & $6934(42)$ & $1107(40)$ & 1146 (43) & $1040(39)$ & $1452(35)$ & $695(49)$ & $1494(51)$ \\
\hline Excellent & $2790(17)$ & $256(10)$ & $735(28)$ & $187(7)$ & $693(17)$ & $178(13)$ & $741(25)$ \\
\hline \multicolumn{8}{|l|}{ TV screen time } \\
\hline$\leq$ half an hour & $3763(23)$ & $679(25)$ & $777(29)$ & $523(20)$ & 791 (19) & $331(24)$ & $662(22)$ \\
\hline $1-2 \mathrm{~h}$ & $8424(51)$ & $1434(52)$ & $1449(55)$ & $1271(48)$ & 2011 (49) & $803(57)$ & $1456(50)$ \\
\hline $3-4 \mathrm{~h}$ & $3190(19)$ & $454(17)$ & $332(13)$ & $617(23)$ & $969(24)$ & $232(17)$ & $586(20)$ \\
\hline$>4 \mathrm{~h}$ & $1099(7)$ & $173(6)$ & $83(3)$ & $252(9)$ & $328(8)$ & $35(2)$ & $228(8)$ \\
\hline $\begin{array}{l}\text { No. of movies seen, mean (SD), } \\
\text { range } 0-50\end{array}$ & $21.21(9.04)$ & $16.46(8.34)$ & $24.84(8.51)$ & $20.54(8.42)$ & $22.81(9.47)$ & $16.74(7.93)$ & $22.88(7.75)$ \\
\hline $\begin{array}{l}\text { Sensation seeking and rebelliousness, } \\
\text { mean (SD), range } 0-4\end{array}$ & $1.31(0.74)$ & $1.21(0.72)$ & $1.0(0.69)$ & $1.43(0.75)$ & $1.53(0.74)$ & $1.01(0.59)$ & $1.40(0.73)$ \\
\hline \multicolumn{8}{|l|}{ Social environment } \\
\hline \multicolumn{8}{|l|}{ Peer smoking } \\
\hline None & $6790(41)$ & $1545(57)$ & $2084(79)$ & $534(20)$ & $446(11)$ & $582(41)$ & $1599(54)$ \\
\hline A few & $4467(27)$ & $723(26)$ & $395(14)$ & $637(24)$ & $1496(36)$ & $366(26)$ & $850(29)$ \\
\hline Some & $2970(18)$ & $311(11)$ & $123(5)$ & $759(29)$ & $1182(29)$ & $313(22)$ & $282(10)$ \\
\hline Most/all & $2247(14)$ & $159(6)$ & $41(2)$ & $727(27)$ & $971(24)$ & $148(11)$ & $201(7)$ \\
\hline \multicolumn{8}{|l|}{ Mother figure smoking } \\
\hline No & $11970(73)$ & $1812(67)$ & $2191(83)$ & $2007(75)$ & $2715(66)$ & $1165(83)$ & $2080(71)$ \\
\hline Yes & $4499(27)$ & $908(33)$ & $456(17)$ & $655(25)$ & $1384(34)$ & $247(17)$ & $849(29)$ \\
\hline \multicolumn{8}{|l|}{ Father figure smoking } \\
\hline No & $10949(66)$ & $1692(62)$ & $2077(79)$ & $1669(63)$ & $2352(57)$ & $1125(80)$ & $2034(69)$ \\
\hline Yes & $5541(34)$ & $1052(38)$ & $567(21)$ & $991(37)$ & $1748(43)$ & $289(20)$ & $894(31)$ \\
\hline \multicolumn{8}{|l|}{ Any sibling smoking } \\
\hline No & $13583(82)$ & $2276(83)$ & $2220(84)$ & $2199(83)$ & $3220(79)$ & $1246(88)$ & $2422(83)$ \\
\hline Yes & $2885(18)$ & $456(17)$ & $418(16)$ & $463(17)$ & $875(21)$ & $165(12)$ & $508(17)$ \\
\hline
\end{tabular}

*Variations in $\mathrm{n}$ are owing to missing values. 
substantially between countries. For example, $9 \%$ of the Icelandic students were ever-smokers, compared with $42 \%$ in the Polish sample. Differences in ever-smoking rates remained after controlling for age and gender, with age- and gender-adjusted prevalences of $0.11,0.26,0.26,0.33,0.35$ and 0.36 for Iceland, the Netherlands, UK, Poland, Germany and Italy, respectively.

\section{Exposure to smoking in movies}

Overall, 71\% of the total 655 movies included at least 1 tobacco occurrence, with a range of 0 to 423 and a mean of 28.5 occurrences. On average, adolescents had seen $21(\mathrm{SD}=9)$ of the 50 movies on their individual list (table 1), which translated into an estimated mean exposure to on-screen tobacco of 1727 (median=1448) occurrences, based on an extrapolation to the respective 250 movies.

Figure 1 shows the distributions for the estimated exposure to smoking in movies. All histograms are positively skewed, with some differences between the countries with regard to the mean amount of exposure (all pairwise comparisons' $\mathrm{p}<0.05$, with the exception of Iceland vs Poland and Italy vs UK). The lowest exposures occurred among German and Dutch adolescents and the highest among those from Iceland and Poland.

We tried to approach the influence of country-specific age ratings on exposure by separating all included movies into "youth-rated" movies (rated for audiences $<16$ years) and 'adultrated' movies (rated for audiences $\geq 16$ years). There were profound differences in the proportion of adult ratings in the country lists of 250 movies with $18 \%$ adult ratings in Iceland, $14 \%$ in the Netherlands, $11 \%$ in Germany, $7 \%$ in the UK, $1 \%$ in Poland and $0 \%$ in Italy, mostly reflecting different rating practices in the countries. In overall tobacco occurrences by age rating, $55 \%$ of the tobacco occurrences in the Icelandic box-office hits were in youth-rated movies, $67 \%$ in the Netherlands, $80 \%$ in the UK, $81 \%$ in Germany and $99.9 \%$ in Poland, and by definition, all tobacco occurrences in Italy were counted in youth-rated movies. Looking at the actual mean exposure from youth-rated movies, the lowest mean was found for Iceland with $74 \%$, followed by the Netherlands with $80 \%$, Germany with $92 \%$, UK with 93\% and Poland and Italy with 100\%.

\section{Associations between study variables}

Table 2 displays the zero-order correlations between the study variables, demonstrating significant crude associations between the central constructs. Ever smoking was positively correlated with exposure to movie smoking $(r=0.20)$ and also significantly correlated with all other study variables, particularly age $(\mathrm{r}=0.33)$, school performance $(\mathrm{r}=-0.27)$, sensation seeking/ rebelliousness $(r=0.41)$, peer smoking $(r=0.54)$ and sibling smoking $(\mathrm{r}=0.23)$.

\section{Association between exposure to smoking in movies and adolescent smoking}

The smoothed lowess curves in figure 2 illustrate the association between exposure to movie smoking and adolescent ever smoking for each country. These show a consistent monotonic increasing relationship between exposure to movie smoking and ever smoking. The shapes of the curves look very similar, showing a generally steeper relationship for lower exposure levels, with the exception of the Icelandic curve that shows a lower slope for lower exposure values and gets a similar slope only for higher exposure values. Different intercepts mirror differences in lifetime smoking prevalence of the countries. For example, in Germany, prevalence of ever smoking rises from 0.1 for low-exposure adolescents to up to 0.5 for high-exposure adolescents, whereas in Iceland, the prevalence rises from 0.02 for low-exposure adolescents to up to approximately 0.18 for high-exposure adolescents.

\section{Multivariate analysis}

Table 3 shows crude and adjusted ORs (AORs) for the relationship between movie smoking exposure and ever smoking. In the crude models, and for all countries, exposure to smoking in the movies was significantly associated with youth ever smoking, as already indicated by the lowess curves. In frequencies, this association translates to $14 \%$ ever smoking in quartile 1 (Q1) compared with $21 \%$ in Q2, 29\% in O3 and $36 \%$ in Q4 Furthermore, in the overall (all countries) adjusted model, adolescents with higher exposure to smoking in movies were significantly more likely to have ever smoked, after controlling
Figure 1 Exposure to smoking in movies among adolescents from six European countries (total $n=16551$ ). Estimation based on tobacco occurrences in each country's 250 most successful movies of the years 2004-2009. Number of seen tobacco occurrences displayed in the $\mathrm{X}$-axes. $\mathrm{M}$, mean, Mdn, median.

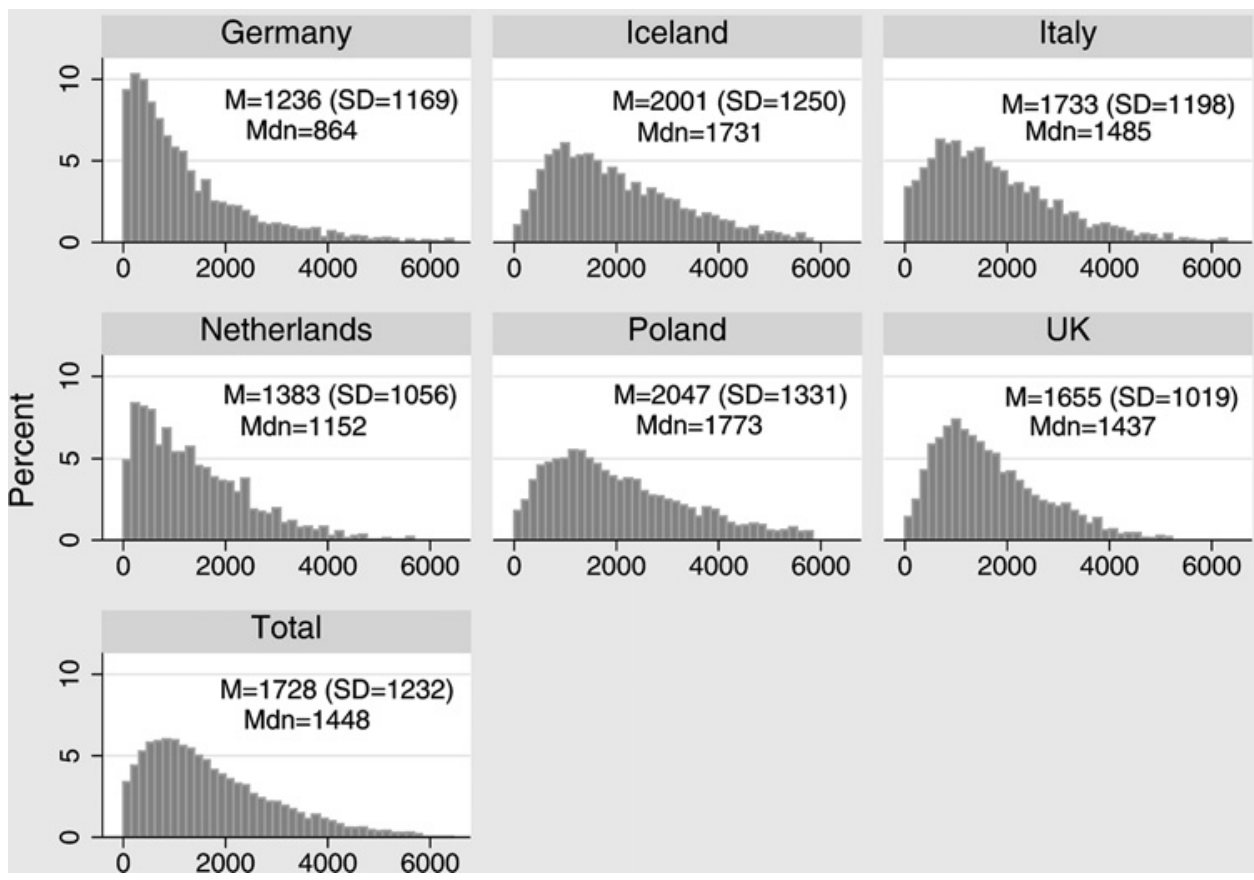


Table 2 Zero-order correlation matrix

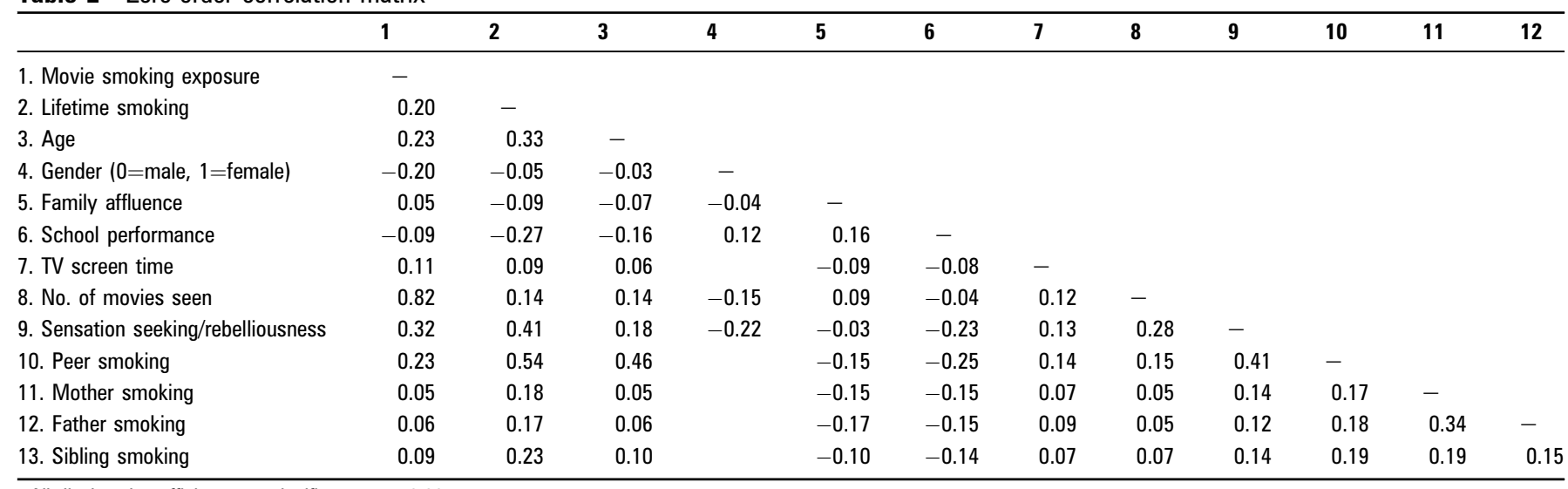

All displayed coefficients are significant at $p<0.001$.

for age, gender, family affluence, school performance, television screen time, number of movies seen, sensation seeking and rebelliousness and smoking within the social environment (peers, parents and siblings). In the adjusted model, predicted frequencies were $25 \%$ ever smoking in Q1 to $28 \%$ in Q2, 31\% in Q3 and $32 \%$ in Q4.

The adjusted relationship with ever smoking was found for higher exposure levels in all countries with some betweencountry differences in the strength of the relationship; for example, the AOR for Polish youths with high exposure (Q3) compared with that for students in the lowest exposure category (Q1) was 1.4 (95\% CI 1.1 to 1.8), whereas the AOR for Scottish students in the highest exposure category (Q4) was 2.8 (1.7 to 4.6) compared with that for students in the lowest exposure category (Q1).

\section{DISCUSSION}

This paper presented the results of a cross-cultural study examining the association between exposure to smoking in movies and youth smoking. The association with ever smoking is remarkably similar to the findings among US, ${ }^{10}$ German, New Zealand ${ }^{9}$ and Mexican ${ }^{13}$ adolescents, with a similar dose-response curve and with adjusted odds of ever smoking being 1.1-2.8 times greater for adolescents with higher exposure. Moreover, the adjusted relationship between movie

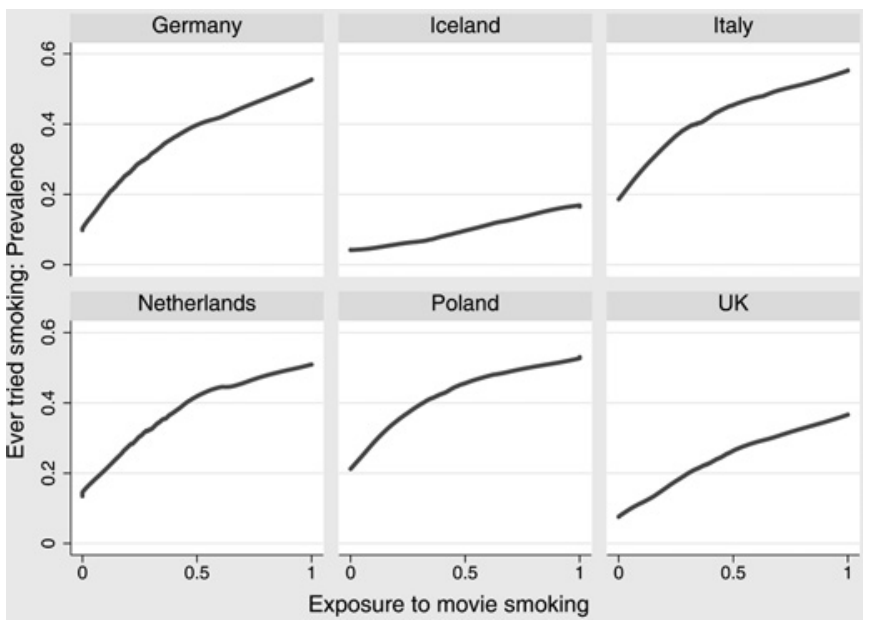

Figure 2 Crude association between exposure to movie smoking and ever-smoking, by country. smoking exposure and ever smoking was found in each countryspecific model. This is remarkable because the countries differ greatly in their tobacco control policies ${ }^{34}$ and therefore also in the process of denormalising smoking in the society. ${ }^{38}$ The findings suggest a consistent movie-youth smoking association regardless of culture or tobacco control approach.

Policies aimed at movie smoking have been addressed by the FCTC. Parties to this agreement have ratified to undertake a comprehensive ban on tobacco advertising, promotion and sponsorship according to Article 13. The implications of Article 13 are that the depiction of tobacco use in films represents a form of tobacco advertising, and Article 13 guidelines recommend that "Parties should take particular measures concerning the depiction of tobacco in entertainment media products, including requiring certification that no benefits have been received for any tobacco depictions, prohibiting the use of identifiable tobacco brands or imagery, requiring anti-tobacco advertisements and implementing a ratings or classification system that takes tobacco depictions into account." 39 Based on the results of this six-country study, it seems there is little reason for a delay in changes to incorporate smoking into the movie ratings systems in European countries. The study revealed a high variation in the rating practices between the countries and confirmed that the clear majority of exposure to movie smoking in European adolescents comes from youth-rated movies, with a range of $55 \%$ (Iceland) to $100 \%$ (Italy and Poland)

There are, of course, several limitations to the current study, the most important one being the cross-sectional design. Crosssectional data do not inform about the temporal sequence of events, that is, if exposure to smoking in movies preceded smoking experimentation or uptake. Temporal antecedence is seen as an important determinant of a causal relationship, but it is not the only one, and there are already a number of longitudinal studies in this area that clearly demonstrate that movie smoking exposure happens before behaviour onset and predicts it.

The present study contributes to the causality question from another direction-unmeasured confounding. First, one advantage of cross-cultural studies is that unmeasured confounding is accounted for by the country-level random effect. In the present context, movie smoking exposure is the constant on a background of many other between-country differences. The consistent finding of a movie smoking effect after the control of country variance is a very important contributor to the causal argument. The second way this study contributes to causality is that the multivariate analyses included the number of movies 


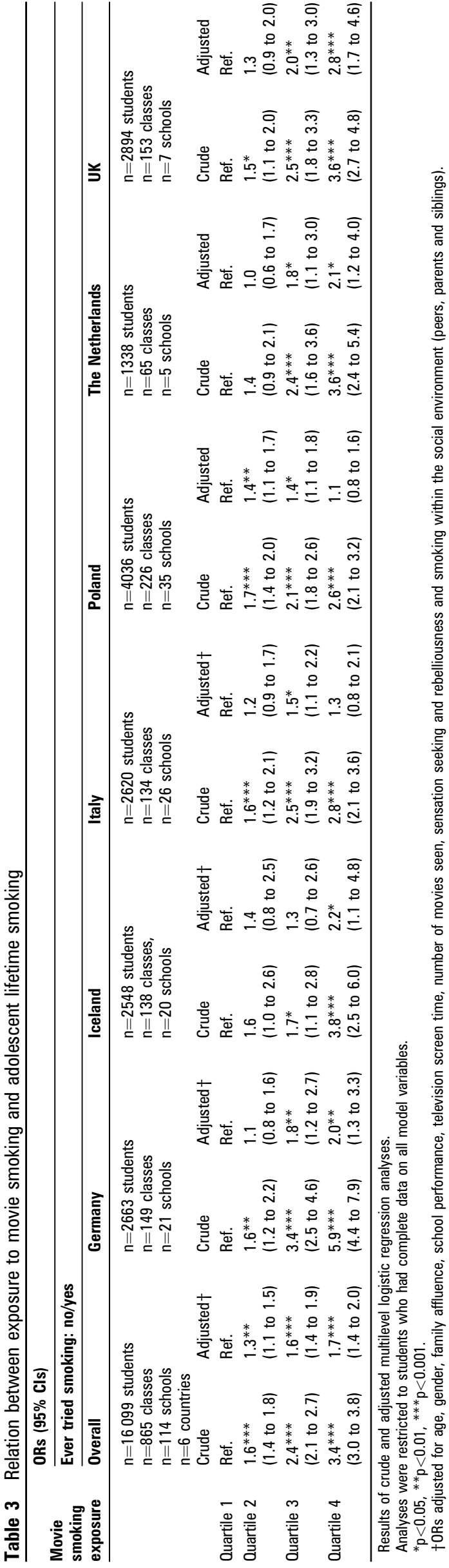

a student had seen as a covariate. This control targets the specificity of the exposure-behaviour link, another key feature of causal arguments in epidemiological research. ${ }^{40} \mathrm{High}$ exposure to movie smoking might only be an indication of high movie exposure in general, which in turn might be the actual cause or another marker variable. That general movie exposure did not eliminate the movie smoking exposure-youth smoking association adds weight to the claim that it is really something about smoking in the movies that is associated with youth ever smoking, adding empirical evidence to the argument that it constitutes a social influence.

Other limitations relate to the assessment of movie smoking exposure that was based on student recall and hence open to error and biases. However, there is no obvious reason for memory distortions to be systematically related to the amount of movie smoking exposure. The same is possible for ever smoking that might also have been misreported but should nevertheless unlikely interact with the non-reactive exposure assessment used in the present study. A further source of imprecision is the content coding of the movies that was performed by different study centres. However, high inter-rater reliabilities ensured that the coding information could be validly used in our correlational analysis. There might also be sporadic variations in the actual content of movies due to countryspecific cuts of scenes. A final issue is the potential bias due to the $14 \%$ unsurveyed students because of absence or missing parental consent. However, response rates varied between countries, from $78 \%$ in Germany to $95 \%$ in Iceland, without any systematic differences in pattern of results.

In summary, the consistency of the association between movie smoking and adolescent smoking in six European countries, despite their substantial differences in culture and tobacco policy, and after covariate control for the number of movies seen, adds further weight to the argument that smoking in movies is an independent risk factor for smoking uptake in youth. Germany, Iceland, Italy, the Netherlands, Poland and the UK have all ratified the WHO FCTC. ${ }^{41}$ Reducing on-screen smoking is one key recommendation in the implementation guidelines of Article 13 of the Framework Convention. The current research findings support this recommendation and provide further scientific evidence in favour for measures to limit on-screen smoking.

Acknowledgements We thank Abita Bhaskar, Daria Buscemi, Lars Grabbe, Roberto Gullino, Leonie Hendriksen, Maksymilian Kulza, Martin Law, Dan Nassau, Balvinder Rakhra, Monika Senczuk-Przybylowska and Tiziano Soldani for coding the movies. We are also thankful to all pupils and staff in participating schools and the survey fieldforces in each country. The Italian centre acknowledges the work of Piera Arata, Silvia Caristia, Diego Concina and Silvia Randino who substantially helped in conducting the study. The Scottish centre acknowledges the work of Catherine Ferrell, Elaine Hindle and colleagues who substantially helped in conducting fieldwork.

Funding European Commission, Ministry of Health of the Federal Republic of Germany. The coding of the US movies was supported by the National Institutes of Health (grant NIH CA 077028). The Scottish fieldwork was supported by additional funds from the UK Medical Research Council (MC_US_A540_0041).

Competing interests None.

Patient consent Obtained.

Ethics approval Study implementation was approved in all six study centres by the respective ethical boards and data protection agencies.

Contributors All authors fulfil the authorship criteria as defined by the Uniform Requirements for Manuscripts Submitted to Biomedical Journals.

Provenance and peer review Not commissioned; externally peer reviewed.

\section{REFERENCES}

1. Ezzati M, Lopez AD. Estimates of global mortality attributable to smoking in 2000 . Lancet 2003;362:847-52. 
2. Lopez AD, Mathers CD, Ezzati M, et al. Global and regional burden of disease and risk factors, 2001: systematic analysis of population health data. Lancet 2006;367:1747-57.

3. Chassin L, Presson CC, Sherman SJ, et al. The natural history of cigarette smoking predicting young-adult smoking outcomes from adolescent smoking patterns. Health Psychol 1990:9:701-16.

4. Conrad KM, Flay BR, Hill D. Why children start smoking cigarettes: predictors of onset. Br J Addict 1992;87:1711-24.

5. Bandura A. Social Foundations of Thought and Action: A Social Cognitive Theory. Englewood Cliffs: Prentice-Hall, 1986.

6. Wakefield $\mathbf{M}$, Flay $\mathrm{B}$, Nichter $\mathrm{M}$, et al. Role of the media in influencing trajectories of youth smoking. Addiction 2003;98(Suppl 1):79-103.

7. Hanewinkel R, Sargent JD. Exposure to smoking in popular contemporary movies and youth smoking in Germany. Am J Prev Med 2007;32:466-73.

8. Hunt K, Sweeting $H$, Sargent J, et al. An examination of the association between seeing smoking in films and tobacco use in young adults in the west of Scotland: cross-sectional study. Health Educ Res 2009:24:22-31.

9. Laugesen M, Scragg R, Wellman RJ, et al. R-rated film viewing and adolescent smoking. Prev Med 2007;45:454-9

10. Sargent JD, Beach ML, Dalton MA, et al. Effect of seeing tobacco use in films on trying smoking among adolescents: cross sectional study. BMJ 2001;323:1394-7.

11. Sargent JD, Stoolmiller M, Worth KA, et al. Exposure to smoking depictions in movies: its association with established adolescent smoking. Arch Pediatr Adolesc Med 2007;161:849-56.

12. Song AV, Ling PM, Neilands TB, et al. Smoking in movies and increased smoking among young adults. Am J Prev Med 2007;33:396-403.

13. Thrasher JF, Jackson C, Arillo-Santillan E, et al. Exposure to smoking imagery in popular films and adolescent smoking in Mexico. Am J Prev Med 2008;35:95-102.

14. Sargent JD, Beach ML, Adachi-Mejia AM, et al. Exposure to movie smoking: its relation to smoking initiation among US adolescents. Pediatrics 2005;116:1183-91.

15. Adachi-Mejia AM, Primack BA, Beach ML, et al. Influence of movie smoking exposure and team sports participation on established smoking. Arch Pediatr Adolesc Med 2009:163:638-43

16. Dalton MA, Sargent JD, Beach ML, et al. Effect of viewing smoking in movies on adolescent smoking initiation: a cohort study. Lancet 2003;362:281-5.

17. Dalton MA, Beach ML, Adachi-Mejia AM, et al. Early exposure to movie smoking predicts established smoking by older teens and young adults. Pediatrics 2009;123 e551-8.

18. Hanewinkel R, Sargent JD. Exposure to smoking in internationally distributed American movies and youth smoking in Germany: a cross-cultural cohort study. Pediatrics 2008;121:e108-17.

19. Jackson C, Brown JD, L'Engle KL. R-rated movies, bedroom televisions, and initiation of smoking by white and black adolescents. Arch Pediatr Adolesc Med 2007;161:260-8.

20. Tanski S, Stoolmiller M, Dal Cin S, et al. Movie character smoking and adolescent smoking: who matters more, good guys or bad guys? Pediatrics 2009;124:135-43.

21. Thrasher JF, Sargent JD, Huang L, et al. Does film smoking promote youth smoking in middle-income countries?: a longitudinal study among Mexican adolescents. Cancer Epidemiol Biomarkers Prev 2009;18:3444-50.

22. Titus-Ernstoff L, Dalton MA, Adachi-Mejia AM, et al. Longitudinal study of viewing smoking in movies and initiation of smoking by children. Pediatrics 2008;121:15-21.
23. Wilkinson AV, Spitz MR, Prokhorov AV, et al. Exposure to smoking imagery in the movies and experimenting with cigarettes among Mexican heritage youth. Cancer Epidemiol Biomarkers Prev 2009;18:3435-43.

24. Sargent JD, Hanewinkel R. Comparing the effects of entertainment media and tobacco marketing on youth smoking in Germany. Addiction 2009;104:815-23.

25. Gibson B, Maurer J. Cigarette smoking in the movies: the influence of product placement in attitudes toward smoking and smokers. J Appl Soc Psychol 2000;30:1457-73.

26. Hanewinkel R. Cigarette smoking and perception of a movie character in a film trailer. Arch Pediatr Adolesc Med 2009;163:15-18

27. Hines D, Saris R, Throckmorton-Belzer L. Cigarette smoking in popular films: does it increase viewers' likelihood to smoke? J App/ Soc Psychol 2000;30:2246-69.

28. Pechmann C, Shih CF. Smoking scenes in movies and antismoking advertisements before movies: effects on youth. J Mark 1999;63:1-13.

29. National Cancer Institute. The Role of Media in Promoting and Reducing Tobacco Use. Tobacco Control Monograph No. 19 (NIH Publication No. 07-6242). Bethesda: US Department of Health and Human Services, National Institutes of Health, National Cancer Institute, 2008

30. World Health Organization. Smoke-free Movies: From Evidence to Action. Geneva: World Health Organization, 2009.

31. Polansky JR, Glantz SA. First-run Smoking Presentations in U.S. Movies 1999-2006. San Francisco: University of California, San Francisco: Center for Tobacco Control Research and Education, 2007.

32. Sargent JD, Tanski SE, Gibson J. Exposure to movie smoking among US adolescents aged 10 to 14 years: a population estimate. Pediatrics 2007;119 e1167-76.

33. Anderson SJ, Millett C, Polansky JR, et al. Exposure to smoking in movies among British adolescents 2001-2006. Tob Control 2010:19:197-200.

34. Joossens L, Raw M. The Tobacco Control Scale 2010 in Europe. Brussels: Association of European Cancer Leagues, 2011.

35. Hibell B, Guttormson U, Ahlstroem S, et al. The 2007 ESPAD Report-Substance Use Among Students in 35 European Countries. Stockholm: The European School Survey Project on Alcohol and Other Drugs, 2007.

36. Sargent JD, Worth KA, Beach M, et al. Population-based assessment of exposure to risk behaviors in motion pictures. Commun Methods Meas 2008:2:134-51.

37. US Department of Health and Human Services. Preventing Tobacco Use Among Young People. A Report of the Surgeon General. Atlanta: US Department of Health and Human Services, Public Health Service, Centers for Disease Control and Prevention, Office on Smoking and Health, 1994.

38. Chapman S, Freeman B. Markers of the denormalisation of smoking and the tobacco industry. Tob Control 2008:17:25-31.

39. World Health Organization. Guidelines for Implementation of Article 13 of the WHO Framework Convention on Tobacco Control (Tobacco Advertising, Promotion and Sponsorship), 2011. http://www.who.int/fctc/guidelines/article 13.pdf (accessed 4 Jul 2011).

40. Hill AB. The environment and disease: association or causation? Proc $R$ Soc Med 1965:58:295-300.

41. Wipfli H, Huang G. Power of the process: Evaluating the impact of the Framework Convention on Tobacco Control negotiations. Health Policy 2011:100:107-15. 


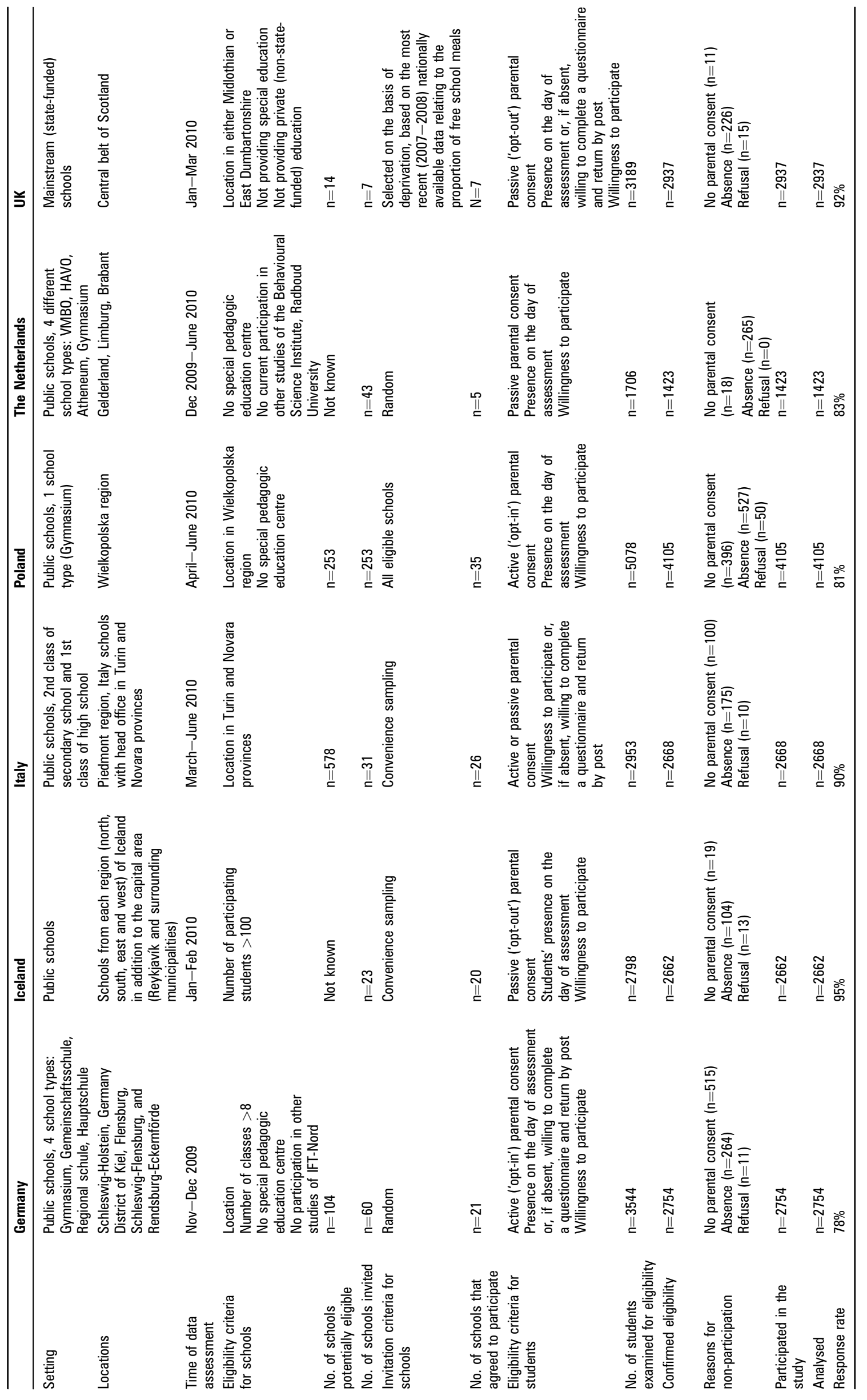


APPENDIX 2

Covariates and their assessment

\begin{tabular}{|c|c|c|}
\hline Variable & Survey question & Response categories \\
\hline \multicolumn{3}{|l|}{ Socio-demographics } \\
\hline $\begin{array}{l}\text { Age } \\
\text { Sex } \\
\text { Family Affluence Scale } \\
\text { (Cronbach } \alpha=0.44 \text { ) }\end{array}$ & $\begin{array}{l}\text { How old are you? } \\
\text { Are you a girl or a boy? } \\
\text { Does your family own a car, van or truck? } \\
\text { Do you have your own bedroom for yourself? } \\
\text { During the past } 12 \text { months, how many times did you travel away on holiday } \\
\text { with your family? } \\
\text { How many computers does your family own? }\end{array}$ & $\begin{array}{l}\text { Years } \\
\text { Boy/girl } \\
\text { No/yes, one/yes, two or more } \\
\text { No/yes } \\
\text { Not at all/once/twice/more than twice } \\
\text { None/one/two/more than two }\end{array}$ \\
\hline \multicolumn{3}{|l|}{ Personal characteristics } \\
\hline $\begin{array}{l}\text { School performance } \\
\text { TV screen time } \\
\text { Number of movies seen } \\
\text { Sensation seeking/rebelliousness } \\
\text { (Cronbach } \alpha=0.70 \text { ) }\end{array}$ & $\begin{array}{l}\text { How would you describe your grades last year? } \\
\text { On a school day, how many hours a day do you usually spend watching TV? } \\
\text { Below is a list of film titles. Please mark if, and how often, you have seen } \\
\text { each film. } \\
\text { How often do you do dangerous things for fun? } \\
\text { How often do you do exciting things, even if they are dangerous? } \\
\text { I believe in following rules (recoded). } \\
\text { I get angry when anybody tells me what to do. }\end{array}$ & $\begin{array}{l}\text { Excellent/good/average/below average } \\
\text { None/ }<1 \mathrm{~h} / 1-2 \mathrm{~h} / 3-4 \mathrm{~h} / \text { more than } 4 \mathrm{~h} \\
\text { Never/once/twice/more than twice } \\
\text { Not at all/once in a while/sometimes/often/very often } \\
\text { Not at all/once in a while/sometimes/often/very often } \\
\text { Not at all/a bit/quite well/very well } \\
\text { Not at all/a bit/quite well/very well }\end{array}$ \\
\hline \multicolumn{3}{|l|}{ Social environment } \\
\hline $\begin{array}{l}\text { Peer smoking } \\
\text { Mother smoking } \\
\text { Father smoking } \\
\text { Sibling smoking }\end{array}$ & $\begin{array}{l}\text { How many of your friends smoke cigarettes? } \\
\text { Does your mother/female guardian smoke cigarettes? } \\
\text { Does your father/male guardian smoke cigarettes? } \\
\text { Do any of your brothers or sisters smoke cigarettes? }\end{array}$ & $\begin{array}{l}\text { None/a few/some/most/all } \\
\text { Yes/no/don't know (coded 'no')/don't have (coded 'no') } \\
\text { Yes/no/don't know (coded 'no')/don't have (coded 'no') } \\
\text { Yes/No/don't have (coded 'no') }\end{array}$ \\
\hline
\end{tabular}

\section{Journal club}

\section{A potential role for tiotropium bromide as an added therapy for adults with uncontrolled asthma}

In this study, the addition of tiotropium bromide to an inhaled glucocorticoid was evaluated as compared with doubling the dose of the inhaled glucocorticoid (primary superiority comparison) or the addition of salmeterol (secondary non-inferiority comparison) in 210 patients with asthma.

Tiotropium use showed a superior primary outcome, as compared with doubling of the inhaled glucocorticoid dose, as assessed by measuring the morning peak expiratory flow rate (PEF), with a mean difference of $25.8 \mathrm{l} / \mathrm{min}$, and superiority in most secondary outcomes, including evening PEF, with a difference of $35.3 \mathrm{l} / \mathrm{min}$, the proportion of asthma-control days, the $\mathrm{FEV}_{1}$ before bronchodilation and daily symptom scores. The addition of tiotropium was also non-inferior to the addition of salmeterol for all assessed outcomes and increased the prebronchodilator $\mathrm{FEV}_{1}$ more than salmeterol.

The study showed that tiotropium, when added to an inhaled glucocorticoid, improved symptoms and lung function in patients with inadequately controlled asthma. Its effects appeared to be equivalent to those with the addition of salmeterol. Additional studies that have sufficient statistical power to evaluate exacerbations and safety events are required to further establish the clinical efficacy of tiotropium in asthma.

- Peters SP, Kunselman SJ, Icitovic N, et al, for the National Heart, Lung, and Blood Institute, Asthma Clinical Research Network. Tiotropium bromide step-up therapy for adults with uncontrolled asthma. N Engl J Med 2010;363:1715-26.

\section{Yasser Falah}

Correspondence to Dr Yasser Falah, 204 West Cotton Close, Northampton NN4 8BZ, UK; ymalrawi82@hotmail.co.uk

Published Online First 10 February 2011

Thorax 2011;66:883. doi:10.1136/thx.2011.159483 